\author{
Ф. 3. Хафизов
}

Тюменский индустриальный университет, г. Тюмень, Россия

\begin{abstract}
Аннотация. В работе изложены основные закономерности тектонического развития территории Среднего Приобья за период от верхов средней юры до эоцена. Показано, что за этот период времени в тектоническом развитии территории были периоды спокойного осадконакопления и весьма активная тектоническая деятельность. В истории тектонического развития Среднего Приобья выделено четыре крупных этапа: спокойные (юра и верхний отдел мела) и два весьма активных с крупномасштабными разнонаправленными движениями, приведшими к существенному увеличению амплитуд структур (от подошвы мела до кровли сеноманского века).
\end{abstract}

Изложена методика корреляционного анализа, использованного при изучении истории тектонического развития территории.

Ключевые слова: анализ мощностей; платформенные структуры; коэффициенты роста; этапы тектонического развития

\title{
FEATURES OF TECTONIC DEVELOPMENT OF STRUCTURES IN THE MIDDLE OB BY CORRELATION OF THICKNESS ANALYSIS
}

\author{
F. Z. Khafizov \\ Industrial University of Tyumen, Tyumen, Russia
}

Abstract. The article is devoted to the main patterns of tectonic development in the Middle $\mathrm{Ob}$ for the period from the tops of the middle Jurassic to the Eocene. It is shown that during this period of time in the tectonic development of the territory there were periods of quiet sedimentation and very active tectonic activity. In the history of the tectonic development of the Middle $\mathrm{Ob}$ four major stages are distinguished: two is quiet (the Jurassic and the Upper Cretaceous) and two are very active with large-scale multidirectional movements that led to a significant increase in the amplitudes of the structures (from the Cretaceous to the roof of the Cenomanian century).

The article describes the methodology of the correlation analysis used in the study of the history of tectonic development in the territory.

Key words: thickness analysis; platform structures; growth factors; stages of tectonic development

Среди факторов, определяющих формирование залежей нефти и газа, одним из важнейших справедливо считается наличие или отсутствие ловушек во время миграции углеводородов. Связь нефтегазоносности с историей формирования ловушек признается почти всеми исследователями, придерживающимися органической теории происхождения нефти и газа и их залежей.

Широко признанным методом изучения истории формирования платформенных структур является анализ мощностей. Теоретические основы метода разработаны профессором МГУ В. В. Белоусовым. Метод основан на том, что мощности осадков зависят от скорости и масштабов погружения дна бассейна осадконакопления, то есть от амплитуды тектонических движений. Эта зависимость позволяет решить и обратную задачу: по мощностям осадков, зафиксированным в разрезе, восстановить масштабы вертикальных тектонических движений. 
Необходимо отметить, что метод имеет целый ряд ограничений, которые необходимо учитывать при окончательных выводах об истории тектонического развития территорий. Так, применение метода в строгом понимании правомерно только в тех случаях, когда имеет место полная компенсация прогибания дна бассейна осадконакоплением, то есть когда мощность осадков в точности соответствует масштабу погружения территории. Однако в природе достаточно часто наблюдаются случаи некомпенсированного погружения, когда толщины осадков значительно меньше размера погружения. Такая характеристика свойственна неокомской части разреза Среднего Приобья, которая формировалась при боковом заполнении бассейна в условиях недостаточного количества осадочного материала, поступающего в бассейн осадконакопления. За счет некомпенсированного прогибания формируется региональный градиент изменения толщин пород, не связанный напрямую с тектоническими движениями. Причем в условиях локальных структур в платформенных регионах с наклоном крыльев, не превышающим 2-3, региональный наклон за счет некомпенсированного прогибания может быть соизмерим с наклоном крыльев локальных структур. В этих условиях пренебрежение региональным градиентом мощностей недопустимо.

Другим фактором, влияющим на точность результатов палеотектонического анализа, является наличие в разрезе перерывов в осадконакоплении. В этом случае толщины осадков не вполне отвечают масштабам погружения из-за того, что толщины осадков искажаются за счет выравнивания поверхности осадков поверхностными водными потоками, в геологическом понимании мгновенными процессами. Таким процессам подвержены отложения тюменской и покурской свит, современные осадки Западной Сибири.

К настоящему времени разработаны и применяются в практике научноисследовательских работ различные методические приемы палеотектонического анализа [1-4]. Строятся графики колебательных движений (В. В. Белоусов), применяется объемный метод (А. Б. Ронов), графики относительного роста структур (Ф. Г. Гурари), графики обобщенных характеристик (В. Б. Нейман). И. И. Нестеров [3] для изучения истории формирования структурных ловушек предлагает использовать зависимости отметок кровли и подошвы стратиграфических комплексов. В полученной зависимости вида $\mathrm{A}=\mathrm{a}+\mathrm{kB}$ он считал значение «а» равным мощности изучаемого комплекса в точке, где его кровля выходит на поверхность, то есть там, где $B=0$, а «k» отражает коэффициент затухания.

Из приведенного неполного перечня видно, насколько разнообразны методы анализа мощностей, используемые при изучении истории тектонического развития локальных структур. Каждый из них обладает определенными достоинствами и недостатками.

Наиболее наглядно историю развития локальных структур можно проследить с помощью изопахической системы карт, где отражаются структурные поверхности всех комплексов в последующие этапы развития структуры. Однако этот метод настолько трудоемкий, что его широкое применение почти невозможным. К примеру, для прослеживания особенностей развития структуры по 10 поверхностям необходимо построить и проанализировать 55 карт изопахит. Сложно представить объем работ для такого анализа, особенно в условиях Западной Сибири, где выявлены многие сотни структур и требуется выполнить анализ по многочисленным стратиграфическим поверхностям.

Отмеченный выше количественный метод эффективен в районах с унаследованным строением структур по всему разрезу, к которым и относится изучаемая территория Среднего Приобья. Западная Сибирь в целом характеризуется исключительно высокой степенью соответствия структурных планов по разным горизонтам. Наблюдаются лишь выполаживание структур и незначительное смещение структуры в части разреза с региональным изменением толщин. Однако эти регио- 
нальные изменения толщин поддаются учету и не могут являться помехой для использования количественных методов анализа истории тектонического развития структур [4].

Количественные методы, основанные на корреляции глубин залегания кровли и подошвы стратиграфических комплексов по сравнению с построением серии карт для изопахического треугольника, обладают целым рядом преимуществ, основные из которых сводятся к следующему:

- $\quad$ количественный анализ позволяет снизить роль субъективного фактора при обработке фактического материала о глубинах залегания стратиграфических толщ и проведении исследований; характеристика истории формирования структур выражается в виде конкретных числовых значений;

- $\quad$ эти методы нетрудоемки и не требуют большого количества структурных построений;

- $\quad$ они позволяют использовать большой массив фактических данных о стратиграфическом расчленении разреза; это преимущество весьма ценно в условиях Среднего Приобья, где количество поисково-разведочных скважин достигает нескольких десятков тысяч.

Корреляционный метод изучения формирования структур, основанный на установлении статистических зависимостей глубин залегания исследуемых поверхностей, использован при анализе истории тектонического развития локальных структур Среднего Приобья в юрско-палеогеновой части разреза. Полученные в результате сопоставления глубин залегания стратиграфических единиц зависимости имеют вид

$$
y=a x+b,
$$

где $y$ - глубина залегания подошвы комплекса пород; $x$ - глубина кровли комплекса. Коэффициент корреляции $R^{2}$ позволяет оценить степень соответствия структурных планов по двум рассматриваемым поверхностям. Детально особенности интерпретации полученных таким путем зависимостей изложены в работе автора [4]. В частности, математически доказано, что коэффициент $а$ указанной зависимости равен отношению амплитуд структуры по двум сравниваемым поверхностям. Этот коэффициент в настоящей статье назван коэффициентом роста $K p$ и в зависимости от его величины свидетельствует о росте или уменьшении амплитуды структуры за время накопления исследуемой толщи: при величине $K p>1$ (то есть при случае, когда амплитуда по подошве комплекса больше, чем по кровле) происходит рост структуры, а при $K p<1$ имеют место расформирование структуры и потеря ее амплитуды.

С использованием корреляционного метода изучена история формирования почти всех локальных структур Среднего Приобья с достаточным для анализа количеством поисково-разведочных скважин (не менее 5-10) по 9 комплексам:

1) оксфорд-кимеридж - между кровлей тюменской и подошвой баженовской свит;

2) титон - между кровлей и подошвой баженовской свиты и ее аналогов;

3) валанжин-баррем - между кровлей баженовской свиты и кровлей алымской свиты и ее аналогов. Между этими поверхностями достаточно много субрегиональных реперов, позволяющих расчленить эту толщу на более мелкие комплексы пород. Однако эта часть разреза характеризуется клиноформным развитием и региональным изменением толщин, в связи с чем корреляционный метод имеет ограничения в применении;

4) апт-сеноман - между кровлей алымской и покурской свит;

5) турон - между кровлей покурской и кузнецовской свит;

6) коньяк-кампан - между кровлей кузнецовской и березовской свит;

7) маастрихт - между кровлей березовской и ганькинской свит; 
8) палеоцен - между кровлей ганькинской и талицкой свит;

9) эоцен - между кровлей талицкой и люлинворской свит.

Ниже кровли тюменской свиты и выше кровли люлинворской по подавляющему большинству локальных структур данных для корреляционного анализа явно недостаточно (ниже тюменской свиты хорошо прослеживаемые горизонты по большинству скважин не вскрыты, а выше люлинворской - отсутствует каротаж), поэтому анализ истории развития локальных структур в этих частях разреза не выполнялся.

По территории Среднего Приобья закартировано изменение по площади двух параметров: коэффициента роста амплитуды локальных структур Кр (рисунок) и коэффициента соответствия структурных планов Ксn. Выполненный анализ истории тектонического развития территории Среднего Приобья показал, что за время от верхней юры и до эоцена были периоды спокойного тектонического развития территории и, наоборот, весьма активные периоды.

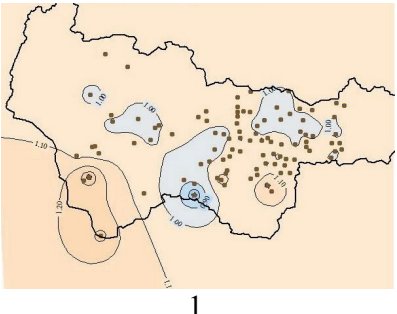

1
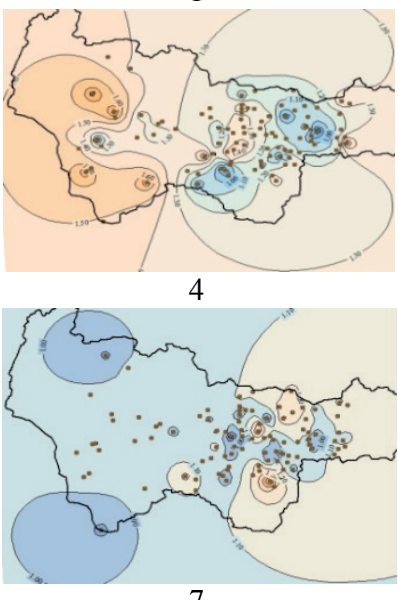

7

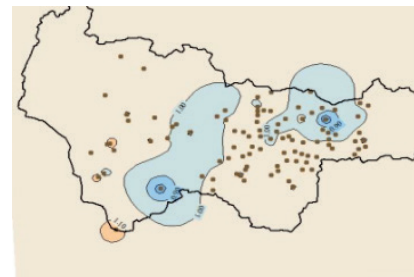

2

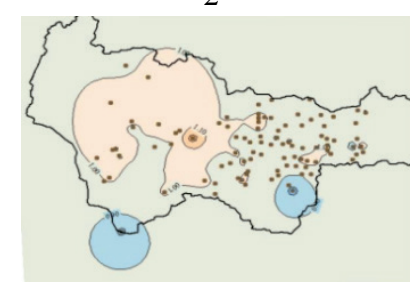

5

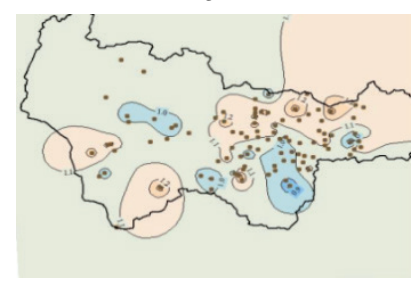

8

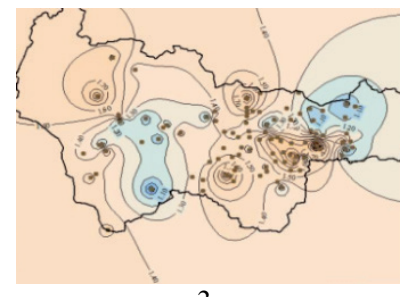

3

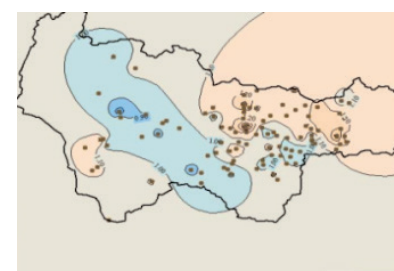

6

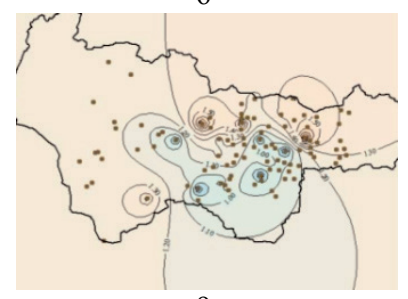

9

Рисунок. Карты тектонического развития локальных структур Среднего Приобья

1 - оксфорд-кимеридж; 2 - титон;3 - валанжин-баррем; 4 - апт-сеноман;

5 - турон; 6-коньяк-кампан; 7 -маастрихт; 8 - палеочен; 9 - эоиен

Так, за период накопления осадков верхней юры (от кровли тюменской и до подошвы баженовской свит) амплитуды подавляющего большинства структур менялись весьма несущественно, в пределах $\pm 10 \%(K p=0,9-1,1)$ (см. рисунок (1)). При этом участки с положительными тектоническими движениями, формирующими локальные поднятия, занимают существенную часть территории Среднего Приобья, а инверсионные движения, приводящие к уменьшению амплитуд существующих структур, имеют место на небольших участках на юге и северо-востоке территории Ханты-Мансийского автономного округа — Югры (см. рисунок (1)), 
на карте эти участки выделены цветом голубых тонов). Имеющиеся исключения из этих данных не всегда подтверждены надежными данными.

Так, по Верхне-Салымской структуре $K p$ составил 0,51, то есть за этот период амплитуда структуры по подошве верхней юры уменьшилась почти вдвое. Но эти данные базируются на материалах всего трех скважин, следовательно, нельзя их считать достоверными. Аналогично, по Тетеревской площади по данным четырех скважин $K p$ составил 1,56 , что означает рост амплитуды поднятия на 56 \%. И эти данные из-за недостатка информации также нельзя считать надежными.

Примерно такая же картина тектонического развития территории наблюдается во время отложения осадков баженовской свиты, причем за этот период тектоника отличается еще большей стабильностью: коэффициенты роста по большинству локальных структур изменяются в пределах $0,95-1,05$, то есть $\pm 5 \%$ (см. рисунок (2)). Имеющиеся исключения базируются на недостаточно надежных данных. По Заозерной и Варьеганской площадям по материалам трех-четырех скважин коэффициент роста структуры составил $0,53-0,57$, а по Поточному, Кечимовскому и Тагринскому поднятиям корреляция осложнена наличием аномальных разрезов баженовской свиты, и ее кровля отбивается неоднозначно, и коэффициент корреляции глубин кровли и подошвы этой толщи не превышает 0,35-0,65.

Совершенно иная ситуация наблюдается по тектоническому развитию Среднего Приобья в период от подошвы мела до апта (от кровли баженовской до кровли алымской свит). Прежде всего, следует отметить исключительно высокую тектоническую активность исследуемой территории в указанный период: коэффициенты роста локальных структур изменяются в пределах от 0,73 (Кошильская структура, то есть почти полуторакратное уменьшение амплитуды) до 3,1 (Руфьеганское поднятие, то есть более чем трехкратное увеличение амплитуды по подошве исследуемой толщи). При этом как положительные, так и отрицательные движения большой амплитуды наблюдаются почти по всей территории исследуемого региона. Максимальные структуроформирующие движения выявлены на западе территории (Пунгинское поднятие, $K p=2,22$, в центральной части (МалоБалыкское и Ватинское поднятия, $K p=2,13-2,31)$ и на востоке (Колик-Еганское и Руфьеганское поднятия, $K p=1,88-3,1)$. Аналогично, отрицательные (инверсионные) движения зафиксированы на западе (Рогожниковское, $K p=0,9$ ), и на востоке (Кошильское, $K p=0,73$ ).

Обращает на себя внимание факт, что в период от кровли верхней юры до кровли алымской свиты на территории Среднего Приобья преобладали в основном положительные движения, которые привели к существенному увеличению амплитуды локальных поднятий (см. рисунок (3)). Площадь территории с положительными тектоническими движениями занимает не менее 70-80 \% всей территории $\mathrm{XMAO} \mathrm{-} \mathrm{Югры} \mathrm{(на} \mathrm{рисунке} \mathrm{эти} \mathrm{территории} \mathrm{выделены} \mathrm{цветом} \mathrm{бежевых} \mathrm{тонов).}$

Примерно такая же ситуация сохраняется и при формировании отложений аптальб-сеноманских отложений. Отличие заключается лишь в том, что редкие очаги отрицательных движений локализуются в основном в центре и на востоке территории (см. рисунок (4)), где выделяются два достаточно крупных участка с преобладанием отрицательных вертикальных движений: в районе Южно-Сардаковского и Новомолодежного поднятий и в районе Верхне-Салымской и Северо-Чупальской структур, не считая нескольких небольших участков (Имилорская, Ореховская структуры). Подавляющая часть территории занята структурами, где преобладали положительные вертикальные движения, причем коэффициенты роста по многим участкам достигали $K p=2,0$ и более.

Почти вся последующая история тектонического развития локальных структур Среднего Приобья (моложе сеноманского века и до палеоцена включительно) отличается существенно более спокойным характером. Так, в туронский век (кузнецовская свита) изменение коэффициентов роста структур не выходят за пре- 
делы $\pm 5 \%$, то есть варьируют в пределах 0,95-1,05 (см. рисунок (5)). В исключительно редких случаях колебания коэффициентов роста могут достигать $\pm 15 \%$, но чаще всего такие случаи связаны или с недостатком информации (Карабашская структура), или с низким коэффициентом корреляции зависимости (Трехозерная). В целом в туронский век все локальные структуры характеризуются положительными движениями, небольшой участок с отрицательными тектоническими движениями зафиксирован в юго-восточной (Ачимовская площадь) части исследуемой территории. Участок с аномально высоким темпом роста структуры $(K p=1,39)$ зафиксирован в центральной части территории (Северо-Селияровская площадь).

Во время формирования отложений березовской свиты (коньяк-сантон-кампан) также преобладали в основном положительные тектонические движения, приведшие к росту амплитуд локальных структур. При этом следует отметить, что в этот период значительная часть исследуемой территории, протягивающаяся с северозапада на юго-восток, характеризуется отрицательными тектоническими движениями, результатом которых явилось уменьшение амплитуд ранее сформировавшихся структур (см. рисунок (6)), причем масштабы такого снижения были достаточно большими - до 25-30 \% (Березовская, Галяновская, Нижне-Шапшинская, Северо-Чупальская, Ватинская и другие структуры). Положительные же движения в этот период, имевшие место на большей части исследуемой территории, были более масштабными. Так, амплитуда Западно-Ловинской структуры за этот период возросла на 39 \%, Западно-Тевлинской — на 31 \%, Тевлинской — на 41 \%, Хохряковской - на 33 \%. Максимальный рост амплитуды отмечен по Колик-Еганской структуре - $61 \%$, однако эти данные базируются на недостаточном объеме информации: удалось привлечь к анализу материалы всего пяти скважин.

К концу мела (маастрихтский век) наблюдается дальнейшее расширение территории с отрицательными тектоническими движениями (см. рисунок (7)): почти на всей западной и центральной частях территории ХМАО-Югры преобладали отрицательные тектонические движения, приведшие к дальнейшему уменьшению амплитуд локальных структур, и только на востоке и юго-востоке изучаемой территории наблюдаются как положительные, так и отрицательные движения. При этом разнонаправленные движения в этот период были достаточно масштабными: коэффициенты роста структур в этот период колеблются от 0,55-0,6 (Яунлорское, Ватьеганское поднятия) до 1,55-1,92 (Кечимовская, Малоюганская структуры). Это хорошо видно на приведенной схеме изменения коэффициента роста структур по площади (см. рисунок (7)): на востоке региона участки с положительными и отрицательными движениями достаточно часто чередуются, образуя мозаичную картину изменения $K p$.

В палеоцене (см. рисунок (8)) общая картина тектонического развития в Среднем Приобье становится более спокойной: почти вся площадь изучаемой территории характеризуется ростом локальных структур, и только на небольших участках на западе (Песчаная, Рогожниковская, Средненазымская структуры) и в центре исследуемой территории (Ачимовская, Малоюганская, Локосовская структуры) отмечены отрицательные тектонические движения. Масштабы отрицательных движений в целом были невелики: Кр изменяется в большинстве случаев в пределах 0,85-0,91, и только на отдельных структурах этот коэффициент снижается до 0,67-0,69 (Колик-Еганская и Ачимовская структуры).

В эоцене размах тектонических движений по локальным структурам, как положительных, так и отрицательных, существенно возрастает. В целом по территории Среднего Приобья преобладают положительные движения, притом по многим структурам вплоть до двойного увеличения амплитуд: коэффициент роста многих структур достигает 1,97 (Сорымско-Иминская) и 2,32 (Ван-Еганская). Одновременно имели место и отрицательные движения, приведшие в эоцене к двойному уменьшению амплитуд. Так, по Западно-Салымской структуре 
коэффициент роста снижается до 0,5 ; по Новопокурской и Кечимовской - 0,58 ; по Северо-Селияровской - 0,6.

Таким образом, в истории тектонического развития локальных структур Среднего Приобья можно выделить четыре крупных этапа. В верхней юре (от кровли средней юры до подошвы мела) территория характеризуется в тектоническом плане спокойным развитием, в целом положительными движениями небольшой амплитуды. Почти весь меловой этап развития (от подошвы мела до кровли сеноманского века) на исследуемой территории преобладали крупномасштабные разнонаправленные движения с преобладанием положительных, приведшие к существенному увеличению амплитуд локальных структур. Начиная с туронского века до конца мела наступает следующий спокойный этап тектонического развития локальных структур. В это время хотя и преобладали положительные движения, масштаб их в целом был невелик. В палеогене наступает новый активный этап развития структур. В этот период преобладали в целом положительные тектонические движения, но на отдельных структурах зафиксированы достаточно масштабные отрицательные движения, приведшие к почти двукратному уменьшению амплитуд поднятий.

Библиографический список

1. Белоусов В. В. Основные вопросы геотектоники. - М.: Госгеолтехиздат. $-1962 .-608$ с.

2. Гурари Ф. Г. О происхождении и классификации локальных структур мезозоя-кайнозоя Западно-Сибирской низменности // Материалы по геологии и нефтегазоносности Западной Сибири. - 1958. № 124. - С. 7-30

3. Нестеров И. И. Вопросы теории осадконакопления платформенных отложений // Труды ЗапСибНИГНИ. - 1968. - № 19. - С. 45-52.

4. Хафизов Ф. З. Повышение эффективности разведки залежей крупных нефтегазоносных комплексов. - Л.: Недра. - 1991. - 264 с.

Сведения об авторе

Хафизов Фаиз Закиевич, д. г.-м. н, профессор кафедры геологии месторождений нефти и газа Тюменский индустриальный университет 2. Тюмень, тел. 89048875364, e-mail: khafizov.faiz@yandex.ru
Information about the author

Khafizov F. Z., Doctor of Geology and Mineralogy, Professor at the Department of Geology of Oit and Gas Fields, Industrial University of Tyumen, phone: 89048875364, e-mail: khafizov. faiz@yandex.ru 